\title{
A Critical Analysis of the Role of Lecture Capture in Online Learning: A Community of Inquiry Perspective
}

\author{
Anna K. Wood, Kate Symons* Jean-Benoit Falisse, Hazel Gray, Albert \\ Mkony
}

*Corresponding author

Anna K Wood, Moray House, School of Education, University of Edinburgh,

Edinburgh, Scotland

Kate Symons*, Mastercard Scholars’ Foundation, University of Edinburgh, Edinburgh,

Scotland, k.symons@.ed.ac.uk

Jean-Benoit Falisse, Centre of African Studies, University of Edinburgh, Edinburgh, Scotland

Hazel Gray, Centre of African Studies, University of Edinburgh, Edinburgh, Scotland

Albert Mkony, Centre of African Studies, University of Edinburgh, Edinburgh, Scotland

Dr Anna K. Wood is an independent researcher specialising in online education and digital pedagogy. Dr Kate Symons is online learning project co-ordinator for the Mastercard Scholar's Foundation at the University of Edinburgh. Dr Hazel Gray is Senior Lecturer in African Studies and Development; Dr Jean-Benoit Falisse is Lecturer in Africa and International Development; and, Albert Mkony is a PhD candidate, all at the Centre of African Studies, University of Edinburgh ${ }^{1}$.

The research for this article was supported by the Edinburgh Principal's Teaching Award Scheme (PTAS) at Edinburgh University, Regular Grant Award (project title: Using lecture capture effectively for online learning).

1 Kate Symons was Principal Investigator on the project, Jean-Benoit Falisse and Hazel Gray were co-investigators. Anna Wood was a researcher on the project and undertook the interviews. Albert Mkony assisted with the literature review and transcription. The authors would like to thank the student research participants who shared their time and insights. 


\section{A Critical Analysis of the Role of Lecture Capture in Online Learning: A Community of Inquiry Perspective}

6963 words, inclusive of tables, references, figure captions, footnotes, endnotes (excluding bibliography).

This paper presents findings from a study into the value of lecture captures for online distance learning courses. Although recording on-campus lectures for oncampus students is increasingly common, there has been little scrutiny of the role of lecture capture in online courses. We address this gap by exploring online distance learning students' perceptions of two types of recorded media; video-tocamera lectures and lecture captures through the lens of the Community of Inquiry (COI) Framework. The study concluded that lecture captures do not contribute to the creation of a COI as they do not substantially increase cognitive, social or teaching presence. However, students were enthusiastic about lecture captures due to the naturalistic lecturing style and the opportunity to learn vicariously. We suggest that these findings should prompt greater consideration of the role of vicarious learning in online education and the tendency to perceive campus-based education as being more 'authentic'. Keywords: word; another word; lower case except names

Key words: Online learning, vicarious learning, community of inquiry, lecture capture, international development, videos

\section{Introduction}

Lecture capture technology has taken hold in the vast majority of UK universities, with $86 \%$ of UK universities having now installed lecture capture in over $90 \%$ of their learning spaces (Newland, 2017 p. 5). The rapid adoption of lecture capture technology across UK higher education can be attributed to assumptions by managers about the cost saving implications of lecture capture, rapid growth in student numbers, perceived student demand, and pressures that universities might be 'left behind' if their competitors adopt the technology (O’Callaghan et al., 2017). The roll out of lecture 
capture technology has generated important debates about intellectual property rights over the recorded material and how to respond to student expectations in the context of the wider commercialization of higher education (Germany, 2012; Freed et al., 2014).

While there are ongoing debates about the advantages and disadvantages of lecture capture in campus-based courses, there has been little scrutiny of the role of lecture capture for on-line distance learning. Online distance learning programmes are defined as programmes that are taught entirely on-line with no requirement to attend teaching on-campus. Such programmes have unique pedagogical challenges (Kebritchi et al., 2017). A common assumption has developed in some areas of University management (partly fuelled by the promises of the industry that provides lecture capture technologies) that lecture capture will facilitate the expansion of on-line distance teaching by reducing the time and cost needed to produce teaching material (Newland, 2017). While lecture videos are a common component of online programmes and their impact on educational outcomes have been researched (Whatley \& Ahmad, 2007; Zhang et al., 2009; Brecht, 2010) there has been little examination of the potential role of video content produced through live lecture capture specifically. The few existing studies suggest that online distance learning students benefit most from purpose-made teaching material which draw fully on digital modalities, and simply showing online students material captured from on campus courses could be considered poor practice (Anderson, 2008; Bates, 2015; Hansch et al., 2015; Koumi, 2006). The roll out of lecture capture has preceded serious engagement with its pedagogical benefits in its relationship with online distance learning.

The research we present in this paper addresses this overlooked issue: the relationship between lecture capture technology and online distance learning from the perspective of online learners. We investigated the advantages and disadvantages of 
using recorded lecture material in online learning by examining student views of two types of recorded lecture material - video-to-camera lectures recorded specifically for on-line students and lecture captures of campus lectures, and analysed our results through the Community of Inquiry (CoI) framework. Our analysis showed that many students in our study were initially enthusiastic about their experiences of watching lecture recordings as part of their on-line courses. This was for three reasons: they preferred the way in which the lecturer spoke to a live audience; they enjoyed hearing interactions between the lecturer and the other students (vicarious learning); and, they felt like they were getting more of what they perceived as the 'real' and 'authentic' campus experience. Despite these positive perceptions we found that lecture capture videos did not contribute to the creation of cognitive, social and teaching presence more than video-to-camera lecture recordings. Our findings show that actual opportunities for vicarious learning were not enhanced with the use of lecture capture material. We interpret the apparent paradox in our results as reflecting the fact that students' enthusiasm for lecture captures stems in part from their tendency to over-privilege the campus teaching experience. While we conclude that online distance learning is not enhanced by the use of lecture capture in contrast to pre-recorded video material, our findings do provide insights into the continued destabilization of the distinction between online learners and the physical campus, and suggests concrete steps in developing online pedagogy.

The paper proceeds as follows: After examining literature related to lecture capture, online learning and the community of inquiry, we discuss our research design, methods and limitations of our study. We then discuss key findings around on-line students’ perceptions of two types of recorded media; video-to-camera lectures and lecture captures that they experienced during two online distance learning post-graduate 
programmes offered by the University of Edinburgh. After a discussion which analyses the findings through the community of inquiry framework, we conclude that the roll out of lecture capture into on-line distance programmes is proceeding without sufficient pedagogical evidence of its benefits for students. We suggest that forms of on-line teaching which draw on fully digital modalities may ultimately generate greater social, cognitive and teaching presence, and discuss further pedagogical questions raised by our research.

\section{Online Learning, the Community of Inquiry and Lecture Capture}

\section{Technology}

The term lecture capture refers to classroom lectures which are recorded via a camera and audio recorder to allow students to watch the video online (Chen \& Wu, 2015 p. 111). Lecture capture policies differ between institutions, but lectures are typically recorded automatically in lecture theatres (with opt out usually available to teaching staff), and constitute the lectures as seen by on campus students. The technologies and practices of lecture capture are distinct from online distance learning activities. Online distance learning refers to the broader practice of teaching distance learning students using digital interfaces and informed by specialist online pedagogies to produce bespoke teaching interactions such as online videos, discussion boards and online activities.

The majority of universities in the UK and beyond have extended their capacity for lecture capture in recent years, and lecturers are encouraged (and in some institutions, obliged) to make use of the technology (Newland, 2017). The benefits cited include: convenience and flexibility for students; the ability to provide additional and archived resources; the ability to allow students with different learning styles to learn at 
their own pace; enhancing engagement in lectures by providing students security that they can listen rather than take detailed notes; help students revise for exams and prepare for coursework; allow active learning in seminars by enabling students to revise lectures before a seminar meeting; and, allow students who miss classes to catch up (Davis, Connolly, \& Linfield, 2009; Groen et al., 2016; Traphagan et al., 2009). Students increasingly expect to be able to use online learning to supplement or even replace lecture attendance, despite the questionable pedagogic rational (Holbrook \& Dupont, 2009). Consequently, it is often suggested that lecture capture is demanded by students and it is increasingly presented as a core part of the technology infrastructure needed to enhance the student experience (Newland, 2017). As a result, many universities are developing policies to guide students and staff on the uses and rationale for the technology. However, views are often polarized between staff concerns related to intellectual property, job security and student and staff and student self-censorship, university managers who mandate use of the technology, and students whose expectations increasingly include lecture capture (Newland, 2017).

Meanwhile, the pedagogic evidence for lecture capture is unclear. The literature consists of a wide variety of often disparate case studies across undergraduate and postgraduate, student cohort and subject area, which makes it difficult to extrapolate and draw general conclusions about the benefits and risks of the technology (Nordmann at el. 2019). There are substantial evidence gaps relating to student attendance, learning behaviour, educational outcomes and student welfare (Chang, 2007). Although students often report a perception that their grades improve as a result of lecture capture, other studies report that lecture capture produces no significant change to final grades (Franklin, 2011; von Konsky et al., 2009, Owston et al., 2011, Schreiber, 2010). The literature is mixed regarding reduces undergraduate attendance, while some studies 
report a reduction in attendance (e.g. Edwards \& Clinton, 2018; Traphagan, Kucsera \& Kishi, 2010), this is critiqued by other studies which suggested that there is little evidence for a relationship between lecture capture availability and students’ willingness to attend lectures (O’Callaghan et al, 2017; Hove \& Corcoran, 2008; Topale, 2016). Lecture capture seems to be most beneficial when supplementing rather than replacing lecture attendance, with students who use captured lectures alone often impeding rather than enhancing their learning (Le et al., 2010). Literature suggests that the technology should be used in a sophisticated and reflexive way as part of a wider teaching programme, rather than simply rolled out to satisfy managerial and student demand (Owston et al. 2011; McLean \& Suchman, 2016).

One way of theorizing the failures of lecture capture as a teaching replacement is that students who simply view lecture capture (regardless of whether they are online or on campus students) may fail to engage in a learning community. The current pedagogic ethos in online learning emphasizes the development of a learning community, in which students are encouraged to participate in discussions with other students and teachers, and the primary role of the instructor is to structure interactions, provide guidance and help scaffold concepts and ideas by encouraging learners to engage in reflection (Mayes \& Fowler, 2006; Delen et al., 2014).

Community of Inquiry (CoI) is a conceptual framework developed by Garrison, Anderson \& Archer (2000, 2001), grounded in a social constructivist perspective which posits that learning is social in nature and that collaborating with others leads to learning on both an individual level and a group level (Jézégou, 2010). Central to CoI is the idea that collaborative interactions are important for the creation of three types of presence; social presence, cognitive presence and teaching presence. Teaching presence refers to elements of teaching practice such as facilitating discourse and direct instruction 
(Anderson, Rourke, Garrison, \& Archer, 2001, cited in Garrison et al, 2010 p. 34). The ability to project oneself as a person in mediated communication is considered central to online learning, stimulating the connection between teaching material and what the other members of the online learning community may be thinking (Biocca, Harms \& Gregg, 2001; Garrison et al., 2000 p. 89). This also applies to the instructor; teachers are encouraged to engage in emotional expression and open communication to foster group cohesion (Lowenthal, 2010; Richardson \& Lowenthal, 2017). Cognitive presence comprises aspects like triggering events which lead to a sense of puzzlement in learners, and inspire exploration, integration and resolution of learning (through connecting and applying new ideas). Social presence includes open communication, group cohesion and affective expression which encourage collaboration, for example through identifying with fellow learners and developing interpersonal relationships, and providing learners and teachers with opportunities to present themselves as 'real people' in asynchronous learning interactions (Garrison, 2009; Stembom, 2018; Gunawardena, 1995 p.151).

Teaching, social and cognitive presence are interlinked and work together throughout the learning process (Akyol \& Garrison, 2008). For example, social presence through digital lectures and discussion boards enhances learners' enjoyment (Benbunan-Fitch \& Arbaugh, 2006), increases and sustains participation (Vonderwell \& Zachariah, 2005), and improves learners’ satisfaction with the online model itself (Benbunan-Fich et al., 2003). Videos provide a positive substitute for face-to-face communication, thereby directly contributing to academic engagement and outcomes (Borup et al., 2012). Online discussion boards help develop affective and open communication, and later to allow for meaningful academic discussion (i.e. social presence allows for a purposeful shift towards academic activities - that is, teaching 
presence) (see Nolan-Grant, 2019). CoI suggests that online social interactions should be structured and systematic - scaffolded with teaching presence and cognitive presence.

Learning can also take place through watching others in learning events “learning from watching others learn” (Mayes et al., 2002 p. 213). There are various definitions of vicarious learning, including watching another learn through experience (such as in medicine or nursing), learning through discussion and discourse, and being able to learn from hearing experts discuss a concept or topic (Roberts, 2010). There are multiple examples of learning events in the literature, but for our purposes we are interested in dialogue, and in particular, the kinds of question and answer format which may occur in on campus lectures, where students are able to interact with their instructor, clarify ideas, and engage in short debates. The idea that hearing dialogues is a more interactive experience than listening passively to lectures has been proposed by Wood et al (2016) and there is evidence that observing dialogues is beneficial for learning (McKendree, Lee, Dineen, \& Mayes, 1998; McKendree, Stenning, Mayes, Lee, \& Cox, 1998). However, the type of dialogue is important, and more research is needed on the length and content of dialogue, and on how to support students to learn from watching dialogue (Muldner et al., 2014).

To sum up, literature on the value of a $\mathrm{CoI}$ in online learning is indicative of a wider pedagogic paradigm in which learning is considered to take place through dialogue and experience. This suggests that learning may take place vicariously (by watching others' learning experience) as well as through the kinds of relational activities encouraged by CoI. However, there is a research gap on the specific role of lecture capture (an otherwise contentious technology) in online learning. This leads us back to the focus of this research, and the question of whether, and how lecture capture contributes to the development of a CoI, and, if it does, whether using lecture capture to 
enhance social, teaching or cognitive presence provides any additional pedagogical value for online learners.

\section{Methodology, Research Context and Limitations}

\section{1. $\quad$ Research context}

This is a small-scale qualitative study using semi-structured interviews with postgraduate online distance learning students. The research participants were all first,second-or third year students in the MSc International Development (distance learning) and the MSc Global Challenges (distance learning) offered by the School of Social and Political Sciences in the University of Edinburgh. The programmes provide interdisciplinary tools from political science, anthropology, sociology, economics and history to understand development practices and institutions around the world. At the time of research, more than 100 students from over 22 different nations were enrolled in the programmes Around $20 \%$ of the students were based in the UK while just over a quarter of the students were from the US and just over a third of students came from countries outside US and North America. The average age of students is 29.95 years old (standard deviation: 5.71), which is older than the equivalent on-campus programme, and most are working a full-time job, often in a related field. A number of the core courses overlap between the two programmes and all courses involve pre-recorded lecture material, asynchronous discussion boards and independent reading. The course activities are designed in a flexible manner so students can choose when to contribute. All students in the study had experienced both camera-to-video lectures and lecture capture recordings in their programmes. While the core courses for the two programmes used camera to video lectures exclusively, students had been exposed to lecture capture in elective courses within the School and in core courses developed by other schools in 
the University. Many of the students had experienced lecture capture in the elective course Key Skills in Development Practice. This was taught in parallel with a campus course and the same instructor integrated lecture capture material made during the campus course into the on-line distance learning version of the course.

\subsection{Methodology}

Semi-structured interviews were carried out with 12 students. All were mature students, taking the course part-time alongside working in related fields. They were geographically dispersed (Europe (5), North and South America (3), Africa (4)) reflecting the location of programme participants as a whole. Participation was voluntary: students were invited to take part in the semi-structured interviews through emails to course lists. These included a link to a short introductory video by the researcher who would be conducting the interviews (who was not a member of teaching staff), and students were reassured that their participation would have no bearing on any teaching or assessment. Their responses were anonymized by the researcher so that teaching staff would not be able to attribute comments. Ethical approval was sought and granted through the School of Social and Political Sciences at the University of Edinburgh.

All interviews took place through Skype, were audio recorded and subsequently professionally transcribed. An interview guide was developed by the research team. Students were asked about their experiences of two different types of video resources: video-to-camera lectures, defined as lectures created especially for online learners, usually consisting of a lecturer discussing the weeks topic with slides which can be viewed by the students; and, lecture captures, defined as in line with Chen and $\mathrm{Wu}$ 
(2015) as classroom lectures, recorded via a camera and audio recorder which are available to students to watch online. They were asked how connected this made them feel to both lecturers and peers, and how useful they felt the resources were for their learning.

\subsection{Analysis}

A constructivist grounded theory approach, in which we began without a priori hypotheses was followed (Charmaz, 2014). Data analysis took place concurrently with data collection, and after initial coding, was used to inform the direction and focus of subsequent interviews. Important codes were noted initially in memos and subsequently as the analysis progressed, we adopted focused coding whereby initial codes were re-evaluated, re-named, merged or added to as appropriated. As data collection and categories were developed, we examined new data alongside old data through a constant comparative method. Finally, we used a process of theoretical sampling and conducted additional interviews with two students. We determined that theoretical saturation has been reached as no new data emerged and the categories were fully developed. Once the categories had been defined, we examined them through the lens of the elements of the Community of Inquiry framework as described above, namely social presence, cognitive presence and teaching presence.

\subsection{Limitations}

Students were primarily asked to compare their experience of video-to-camera recordings with lecture captures. From this starting point, it is perhaps not surprising that students felt that there were some advantages to lecture captures, as these give a more varied experience, both visually and orally. Students often respond positively when asked if they want more of a particular thing, for example, focus groups with 
students which return results claiming that students want more lecture capture have been used to guide policy decisions enforcing lecture capture on teaching staff. Basing pedagogic decisions on student preferences alone is therefore risky. The limited sample size and the self-selected nature of research participants is also a notable methodological limitation. The decision to undertake the research with a small sample of students was partly guided by the need to limit interference with teaching. Further, the small sample size helped in gaining a sense of gradual repetition of key ideas as the interviews went on, but it must also be noted that this paper is exploratory in nature, intended to respond quickly to the rise of lecture capture as a recent and substantial development in higher education.

\section{Findings}

Eight students expressed enthusiasm for the use of lecture captures in online courses, two disliked the idea, and two were did not express strong feelings either way. Discussions about teaching and learning online were nuanced with both advantages and disadvantages of lecture captures raised by all students. Analysis of this data led to the development of three central themes related to students' experience of lecture captures compared to video-to-camera lectures: Speech delivery style; listening in on class discussions; and, valuing intentionality created video resources. We discuss these themes in turn below, before moving to a discussion of what the findings mean for teaching international development online, and some broader implications for online pedagogy.

\subsection{Speech Delivery Style}


The first theme concerns the difference that students noted in the lecturer's style of speech and delivery in the lecture captures compared to the video-to-camera recordings. Students felt that in the lecture captures, the lecturer was more likely to be enthusiastic and passionate; in contrast, in the video-to-camera lectures, the speech was often felt to be monotone. For example, Student 3 reported that "some people really come alive when they're in the classroom and talking. Whereas I think it feels really awkward to sort of just be talking at a computer in like monologue for half an hour”. Similarly, Student 10 reported that a lecturer viewed through lecture capture seemed “quite passionate speaking to his students, and you could feel that kind of passion... it will really inspire actually, speaking like that to the real people in a room”. This student went on to say that they were able to feel that passion as well. As these quotes show, the difference in the style of speech for each type of video was attributed to the presence or absence of a live audience.

Another difference noted by students between the two types of recordings was the degree of spontaneity. Students noted a preference for when the lecturer was speaking from the top of their head, which tended to happen in lecture captures of live lectures. In contrast students felt that in video-to-camera recordings were being read from a prepared script or notes, which contributed to the feeling that the delivery was more monotone, and that, crucially, this would not be the case in a lecture hall. As Student 1 explained:

Natural speech is way easier to listen to and maintain engagement with as opposed to reading text. and I'm not sure, maybe they're not reading but I think I can tell that they're reading.... I don't know if they would do that in class. 
When students felt that the lecturer was reading from a script, they commented that they would rather read the script for themselves, implying that they expect something more from a video than just transfer of information. The tendency towards more scripted or carefully prepared lectures in the video-to-camera recordings resulted in some students feeling that the speech in the recordings was less 'natural'. Student 1 went on to explain how the tangents and more personal aspects of spontaneous speech helped them to learn.

I want the ums and I want the tangents. That's natural, that's how you learn, that's how you pull in, you know, interesting information is going off on tangents, talking about personal experience, things that you would share in a lecture.

The different styles of speech had a number of consequences for students. Speech that was more monotone and less natural was felt to be less likely to maintain their attention. Conversely spontaneous speech was felt by some students to be evidence of the competence of the lecturer.

I prefer when the lecturer kind of speaks from the top of his head because that tells you that they know the topic.......that makes me kind of believe the lecturer right, or pay attention to what they are saying because that creates kind of the trust to his or her competence (Student 2).

In sum, students reported that hearing naturalistic speech delivery style was more interesting, sparked more passion for learning and created a greater impression of competence in the lecturer.

\section{2. $\quad$ Listening in on Class Discussions}

Students felt that an advantage of lecture captures was that it offered the opportunity to hear interactions that took place during the live on-campus classes. The dialogue present in the lecture captures was contrasted with the monologue of video-to-camera lectures, 
and was felt to be the key differentiator between the two format. Student 2 explained that on campus teaching gives greater opportunity for student-teacher dialogue:

[On-campus lecture capture discussions are] not just a one-way communication. You know, the lecturer is not challenged in just a twenty-minute recording....... [so it's] a different level of interaction and debate.

Students felt that hearing other students' questions, both ones that they hadn't thought of and ones that they themselves would like to ask would be particularly beneficial for their learning. For example, this student reported that:

[I think that lecture captures] would have been really effective and helpful for me ....to listen in on that dialogue and sort of real life feeling of, you know, other people are studying this and everybody's talking about it and it's not just me in this one video. [Student 1]

Another student highlighted the importance of hearing questions asked and answered as a way to prompt new learning:

So, the person in your audience might ask the question that wouldn't occur to me, so you learn that way I think from other people thoughts and ideas. [Student 10]

A similar point was raised by a different student, who wished to see their questions reflected in class discussions:

And you can at least listen for their questions whenever they ask about the questions which they bring out. So I believe those are also interesting....because I feel like I connect like I'm in the lecture. And sometimes actually the questions someone asks at the end of the lecture is perhaps a question I had in mind too. [Student 5] This was a pervasive theme: that students felt that the lecture captures were more interactive than the video-to-camera lectures. This was true even though they 
acknowledged that they were not able to take part in the interactions themselves, as commented by this student:

[I]t feels a little bit more interactive. Even though I'm not part of the interaction I can feel more interaction there so that's really helpful.” [Student 4]

Overall, the views presented in this sub-section capture how online students feel about witnessing and learning from interaction that takes place in an on-campus teaching environment. There is a subtle but important distinction between students reporting feelings of connectedness based on viewing others' interactions, compared to being part of a genuine community of inquiry in their own right.

\section{3. $\quad$ Valuing Intentionality Created Video Resources}

In contrast to the advantages of lecture captures discussed above, students felt that a major problem with lecture captures was that they were not created purposely for their course (even though they may be edited), unlike video-to-camera lectures. Students stated that videos that had been created intentionally for them made them feel more connected, both to the lecturer and to the course. For example, a student commented that:

The primary focus [in lecture captures] is the audience and I'm getting it like second hand. Whereas if [lecturers] are staring into a webcam, the focus is very much on the people that they're delivering it to at a distance. It feels like it’s for you [Student 9]. It was also important to students to feel that the lecturer was putting time and effort into creating these resources for them, and this was often compared to the effort that lecturers would be putting into giving an on-campus lecture:

They are made with the online students in mind, with a topic in mind. So, I can see that they are kind of made specifically for a specific subject or for a specific course. So, somebody did take the time [Student 2]. 
Students also equated the effort that they felt the lecturers should put into the course with getting value for money: they saw lecture captures as an easy option for the lecturers as they would be giving the lecture on campus anyway.

Masters is very expensive and it's nice to know that they've put in a lot of, you know, because there are naturally things that we're not getting, but the campus students get, so I think it's good to know that, you know, they prepare specific bits for the online students and we're getting, you know, that quality' [student 7]

The quality of recorded material came up as an important issue in many of the student interviews and they referred to weaknesses such as poor audio or video quality, lack of synchronisation between PowerPoint slides and audio. Students pointed to the variability of quality in recorded material and praised sophisticated lecture capture material that they had experienced consisting of a video recording of the lecturer together with a feed of the slides and good quality audio. Students commented that a purpose made video was more likely to be well thought out and tailored to their specific needs as online students. For example:

[Purpose made teaching material] make it feel a little more cohesive and intentional. Whereas with some of the other ones, it feels like...oh we recorded this for something else so like let's just use it [Student 3].

This is important as the characteristics of the on-campus students tend to differ from the online students. On-campus students are likely to be younger and to be studying fulltime whereas the online students are often older and are studying part-time alongside a full-time job while also working in a related field. This means that students expect material to be immediately relevant in a short timeframe and the learning points need to be directly, clearly and concisely communicated. Moreover, as this next student points out, the specific needs of the students on the two international development programmes are also important. As explained in section 3, most of the students on the programmes 
were based outside the UK and face specific challenges and requirements around technological access, accessibility of data, and available time (Spiegel et al 2017). As this student explains, these needs and positionalities are more likely to be catered to if teaching materials are purposely created:

I would say..... that the videos that are made for the course are better. I think whoever makes the videos understands why they are made, so they cater specifically to the students who will be, you know, not in a classroom, and I guess they understand what some of the challenges would be [Student 8].

As student 8 points out here, this is not just about understanding the challenges and opportunities that are inherent in learning online, but about catering to the specific characteristics of the students taking these two post graduate programmes.

We should also point out that some students found that videos of on-campus lecturers could be made in such a way that they are tailored to both kinds of audiences, referring to lectures that they had seen online which did this effectively, such as on campus lectures which also acknowledge that online students are viewing, and allow online students to pose questions via pre-lecture email or instant messaging. In these examples the lecture has been planned to be viewed by both online and on-campus students, the lecturer refers directly to the online students and makes sure that the content is relevant to them. This may present opportunities where there is a course with a similar curriculum and time-scale for on-campus and online students, or where there are key course highlights (such as a prominent guest speaker) which can be made accessible to on campus and online students simultaneously through creative and inclusive use of lecture capture. For more general material, it may be difficult to effectively tailor the course for the different characteristics of the student cohorts described above. 


\section{Discussion and Pedagogic Implications}

Students' perceptions of lecture captures and video-to-camera lectures were evaluated through the lens of the three elements of the CoI framework: Teaching, cognitive and social presence. Turning first to discuss our findings in relation to teaching presence, throughout the interviews we found that students preferred the style of the lecturers' discourse in the lecture captures as they felt that it was more enthusiastic, more natural and more spontaneous. Students felt that this resulted in them finding it easier to pay attention to the lecture. Our finding that students experience the speech in lecture captures as being more natural than in video-to-camera lectures creating an increased instructor presence through enhanced emotional expression. This aspect of students experience does not relate directly to any of the three indicators of teaching presence proposed by Anderson (2001): design and organisation, facilitating discourse, and direct instruction. Nevertheless, as is pointed out in Anderson's research (ibid), as the teacher is a member of the Community of Inquiry, behaviours which develop teaching presence overlaps with the production of social presence. This has led to the concept of instructor social presence as an element of the Community of Inquiry Framework (Lowenthal, 2010; Richardson \& Lowenthal, 2017; Swan \& Shih, 2005). Their preference may also indicate greater open communication as students commented that they felt it was easier to approach an instructor (by e-mail for example) if they feel that they know them from watching the videos. However, this only applies if the students' normal lecturer is giving the lecture capture. If a different lecturer has been recorded, perhaps in the role of a guest lecturer, then there will be no effect on course instructor social presence.

Our research also showed that students strongly preferred resources which were made purposely for them, and which were therefore tailored to their needs both as 
online learners and as members of a particular cohort of students. Lecture captures did not fulfil this as they were generally incorporated into learning resources after the lecture had been recorded, rather than planned in advance. Incorporating online and on campus students into the same lecture through lecture capture (for example, though inviting questions from online students pre-recording which are answered by the lecturer in the recording, or ensuring online students are acknowledged through directing the lecture to them as part of the audience) is certainly achievable, and may benefit online students through allowing them access to special guest speakers and other special on-campus events. This may also allow students to feel more connected to the lecturer if the lecturer giving the lecture captures is the core lecturer on the course. However, there is no evidence from this data that offering students lecture captures instead of video-to-camera lectures increases teaching presence as originally defined. In fact, it may actually decrease the impact of teacher presence.

Considering cognitive presence, we found that students were enthusiastic about the opportunity to listen in on dialogue between the lecturer and the students in the lecture captures. Students felt that hearing dialogue, particularly student questions, was valuable to their learning. This experience was considered more interactive than videoto-camera lectures, even though online students themselves could not participate in the dialogues. As discussed in section 3, many have proposed the idea that learning through dialogues is beneficial for learning. The extent to which this applies to the short question and answer exchanges common in lectures is unclear, however, if students are thinking more deeply about the material and hearing different perspectives then it may be beneficial to their learning. However, we are concerned here specifically with cognitive presence within a community of inquiry, in which discussion with peers is a critical feature. As Garrison (2009) pointed out, the core of cognitive presence is 
meaningful discussion and reflection with one's peers and colleagues in an educational community. Based on this definition of cognitive presence we conclude that it is not enhanced by lecture captures as they do not increase the possibility of interactions with their peers, even though the experience may feel more interactive for the observer.

Finally, with regards to social presence, we consider that this aspect of the $\mathrm{CoI}$ is intrinsically linked to interactions with others. In this work, we found no evidence that watching lecture captures rather than video-to-camera lectures increased either interactions with peers or connections to them, and we therefore conclude that lecture captures do not enhance social presence. We note however that there was a suggestion from some students that the dialogue from the on-campus classes would trigger more discussion on the discussion board, which would be possible if the lecture capture and discussion board were designed purposely to work together. For example, Nolan-Grant (2019) re-designed a course based on CoI principles in which videos were explicitly related to the discussion board through prompts. This intervention resulted in increased social and cognitive presence, as measured by the number of posts on a discussion board and by the proportion of videos watched.

The central question in this research concerns whether lecture captures can have an impact on the creation or enhancement of a community of inquiry for online students. Our discussion above has indicated that there is little impact on social, cognitive or teaching presence, and introducing lecture captures to online learning environments does not lead to an increase in meaningful connections, discussion or communications amongst students and their lecturer. Although students commented that they felt that watching lecture captures was a more interactive experience, online students can only ever be passive observers of the learning event being captured, a community of which they are not a part. Online students are not able to be involved in 
interactions within this learning community and this means that they are not equal participants, that they may feel, as student 9 commented, "like a second-class citizen”. Lecture captures do not increase the opportunities for students to develop relationships within their own learning communities, either with their lecturers or with their peers. We therefore conclude that overall there is no evidence that using lecture captures in online courses enhances the Community of Inquiry for online learners.

Nevertheless, our research raised broader pedagogic implications and questions regarding the role of watching dialogue for online students. In particular, we identify a theme, presented in section 4.2, which suggests that online students appreciate listening in on class discussions. This may imply that there are opportunities to incorporate vicarious learning, including some lecture capture, into the design of online learning. So, while overall our study confirms research that lecture capture should not be used simply to replace specialist online teaching, it should not be concluded that there is absolutely no value in using them at all in online teaching. For example, recording question and answer sessions with a guest lecturer could provide a valuable dimension for online students who might otherwise miss out on a unique perspective from a practitioner in the field, and lecture capture could also be used to incorporate online students in special on campus events and guest speakers.

\section{Conclusion}

The focus of this research has been students' views on lecture capture, ranging from the use of lecture captures as a whole-scale replacement for video-to-camera lectures, to the occasional use of lecture capture as part of a wider bespoke online course. The pedagogical reflection on why lecture capture should be used (in online and in on campus teaching) has been very scant, and the main driver seems to be about cost 
effectiveness rather than any serious engagement with the specific challenges facing online distance learning students. This small-scale, qualitative study of two online MScs in International Development and Global Challenges has partly addressed this lack of critical engagement with lecture capture by exploring how lecture captures might be used in online teaching, and whether there is any pedagogic justification for including this kind of teaching material in online distance courses.

Overall, the study concluded that there was no increase in the opportunity for meaningful interactions, and therefore no significant increase in either teaching or cognitive presence, and no evidence of an effect on social presence. We conclude that introducing lecture captures to online learning environments does not lead to an increase in meaningful connections, discussion or communications amongst students and their lecturer. This is important because it runs counter to the discourse of instrumentalization of lecture capture and online learning, arguably present in university management, which views lecture capture as a ‘quick fix’ for student satisfaction, and online learning as an easy and cost-effective way to increase student numbers.

However, our study did take the views of students who liked lecture capture seriously, and explored the implications of these views. Our study highlighted the benefits of providing opportunities to online students to learn vicariously through watching on-campus discussions. However, this does not imply that lecture capture is the right mode of delivery, not least because recording on-campus interactions between students and teachers (rather than just lectures) would exacerbate the substantial contestation over lecture capture discussed in section 2. A broader concern we have about the use of lecture captures for online learning is that they may lead to (or further encourage) the privileging of on-campus modes of teaching while sidelining the potential benefits offered by digital education (Ross \& Sheail, 2017). This may lead to 
students viewing, for example, synchronous face-to-face discussions as more valuable than asynchronous text-based interactions, rather than seeing them as a valid alternative with different affordances. Nevertheless, our study has led us to reflect on alternative opportunities for vicarious learning using digital videos such as recorded question and answer sessions which could also be scaffolded with other elements of a community of inquiry. It remains an open question, and an avenue for future research, whether students in a well-designed, digitally conceived online course, might feel differently about lecture captures. We suggest that if a community of inquiry is established in which students can be interactive and feel connected to others, online students would be less enthusiastic about lecture captures being part of their course content.

\section{References}

Anderson, T. (Ed.). (2008). The theory and practice of online learning. Athabasca University Press.

Anderson, T., Liam, R., Garrison, D. R., \& Archer, W. (2001). Assessing teaching presence in a computer conferencing context. Journal of the Asynchronous Learning Network, 5 (2).

Akyol, Z., \& Garrison, D. R. (2008). The development of a community of inquiry over time in an online course: Understanding the progression and integration of social, cognitive and teaching presence. Journal of Asynchronous Learning Networks, 12, 3-22.

Benbunan-Fich, R. \& Arbaugh, J.B., 2006. Separating the effects of knowledge construction and group collaboration in learning outcomes of web-based courses. Information \& Management, 43(6), 778-793. 
Benbunan-Fich, R., Hiltz, S.R. and Harasim, L. (2005). The online interaction learning model: An integrated theoretical framework for learning networks. Learning together online: Research on asynchronous learning networks, 19-37.

Biocca, F., Harms, C., \& Gregg, J. (2001). The networked minds measure of social presence: Pilot test of the factor structure and concurrent validity. Paper presented at Fourth Presence International Workshop, Philadelphia, PA.

Borup, J., West, R. E., \& Graham, C. R. (2012). Improving online social presence through asynchronous video. The Internet and Higher Education, 15(3), 195-203.

Brecht, David (2012) Learning from Online Video Lectures Journal of Information Technology Education, Innovations in Practice, 11, 227 - 250.

Brooks, C., Erickson, G., Greer, J. \& Gutwin, C., 2014. Modelling and quantifying the behaviours of students in lecture capture environments. Computers \& Education, 75, 282-292

Chang, S., (2007). Academic perceptions of the use of Lectopia: A University of Melbourne example. In ICT: Providing Choices for Learners and Learning. Proceedings of Ascilite, Singapore 2007.

Charmaz, K., 2014. Constructing Grounded Theory. Sage.

Chen, C.M. \& Wu, C.H., 2015. Effects of different video lecture types on sustained attention, emotion, cognitive load, and learning performance. Computers \& Education, 80, 108121.

Christensen, C.M. \& Eyring, H.J., 2011. The innovative university: Changing the DNA of higher education from the inside out. John Wiley \& Sons.

Davis, S., Connolly, A., \& Linfield, E. (2009). Lecture capture: Making the most of face-toface learning. Engineering Education. V. 4, 2, 4-13 
Delen, E., Liew, J., \& Willson, V. (2014). Effects of interactivity and instructional scaffolding on learning: Self-regulation in online video-based environments. Computers \& Education, 78, 312-320.

Edwards, M.R. \& Clinton, M.E., 2019. A study exploring the impact of lecture capture availability and lecture capture usage on student attendance and attainment. Higher Education, 77(3), 403-421.

Franklin, D.S., Gibson, J.W., Samuel, J.C., Teeter, W.A. \& Clarkson, C.W., 2011. Use of lecture recordings in medical education. Medical Science Educator, 21(1), 21-28

Freed, P.E., Bertram, J.E. \& McLaughlin, D.E., 2014. Using lecture capture: A qualitative study of nursing faculty's experience. Nurse education today, 34(4), 598-602

Garrison, D. R. (2009). Communities of inquiry in online learning. In Encyclopaedia of Distance Learning, Second Edition. 352-355. IGI Global.

Garrison, D. R., Anderson, T \& Archer, W. (2000) Critical Inquiry in a Text-Based Environment: Computer Conferencing in Higher Education. The Internet and Higher Education 2(2-3), 87-105.

Garrison, D. R., Anderson, T \& Archer, W. (2001). Critical Thinking, Cognitive Presence and Computer Conferencing in Distance Education. American Journal of Distance Education 15(1), 7-23.

Garrison, D. R., \& Cleveland-Innes, M. (2005). Facilitating cognitive presence in online learning: Interaction is not enough. The American Journal of Distance Education, 19(3), 133-148.

Garrison, D.R., Cleveland-Innes, M. \& Fung, T.S., 2010. Exploring causal relationships among teaching, cognitive and social presence: Student perceptions of the community of inquiry framework. The Internet and Higher Education, 13(1-2), 31-36. 
Germany, L., 2012. Beyond lecture capture: What teaching staff want from web-based lecture technologies. Australasian Journal of Educational Technology, 28(7), 1208-1220.

Groen, J.F., Quigley, B. \& Herry, Y., 2016. Examining the Use of Lecture Capture Technology: Implications for Teaching and Learning. Canadian Journal for the Scholarship of Teaching and Learning, 7(1), Article 8.

Gunawardena, C. N. (1995). Social presence theory and implications for interaction and collaborative learning in computer conferences. International Journal of Educational Telecommunications, 1(2/3), 147-166.

Holbrook, J., \& Dupont, C. (2009). Profcasts and class attendance-Does year in program matter?. Bioscience Education, 13(1), 1-4.

Jézégou, A. (2010). Community of inquiry in e-learning: A critical analysis of Garrison and Anderson model. Journal of Distance Education, 24(3), 1-18.

Lowenthal, P. R. (2010). The evolution and influence of social presence theory on online learning. In Social computing: Concepts, methodologies, tools, and applications (pp. 113-128). IGI Global.

McLean, J.L. \& Suchman, E.L., 2016. Video lecture capture technology helps students study without affecting attendance in large microbiology lecture courses. Journal of Microbiology \& Biology Education, 17(3), 480.

Mayes, T., Dineen, F., McKendree, J. and Lee, J., 2002. Learning from watching others learn. In Networked learning: perspectives and issues (pp. 213-227). Springer, London.

Mayes, T. \& Fowler, C., 2006. Learners, learning literacy and the pedagogy of e-learning. Digital literacies for learning, 26-33. 
McKendree, J., Lee, J., Dineen, F., \& Mayes, T. (1998). The vicarious learner: helping students listen in to learn. Distance Learning '98. Proceedings of the Annual Conference on Distance Teaching \& Learning, 14th, Madison, WI, August 5-7, 1998

McKendree, J., Stenning, K., Mayes, T., Lee, J., \& Cox, R. (1998). Why observing a dialogue may benefit learning. Journal of Computer Assisted Learning, 14(2), 110-119.

Muldner, K., Lam, R. \& Chi, M.T., 2014. Comparing learning from observing and from human tutoring. Journal of Educational Psychology, 106(1), 69.

Newland, B., 2017. Lecture Capture in UK HE 2017. A HeLF Survey Report.

Nolan-Grant, C. R. (2019). The Community of Inquiry framework as learning design model: A case study in postgraduate online education. Research in Learning Technology, 27.

Nordmann, E., Calder, C., Bishop, P., Irwin, A. \& Comber, D., 2019. Turn up, tune in, don’t drop out: The relationship between lecture attendance, use of lecture recordings, and achievement at different levels of study. Higher Education, 77(6),1065-1084.

O’Callaghan, F.V., Neumann, D.L., Jones, L. \& Creed, P.A., 2017. The use of lecture recordings in higher education: A review of institutional, student, and lecturer issues. Education and Information Technologies, 22(1), 399-415.

Owston, R., Lupshenyuk, D., \& Wideman, H. (2011). Lecture capture in large undergraduate classes: Student perceptions and academic performance. The Internet and Higher Education, 14(4), 262-268.

Pucciarelli, F. \& Kaplan, A., 2016. Competition and strategy in higher education: Managing complexity and uncertainty. Business Horizons, 59(3), 311-320.

Richardson, J. C., \& Lowenthal, P. (2017). Instructor Social Presence: Learners’ Needs and a Neglected Component of the Community of Inquiry Framework. Social Presence in Online Learning: Multiple Perspectives on Practice and Research, Stylus Publishing LLC. 32-44. 
Roberts, D., (2010). Vicarious learning: a review of the literature. Nurse Education in practice, 10(1), 13-16.

Ross, J., \& Sheail, P. (2017). The ‘campus imaginary’: Online students’ experience of the masters dissertation at a distance. Teaching in Higher Education, 22(7), 839-854.

Spiegel, S., Gray, H., Bompani, B., Bardosh, K., \& Smith, J. (2017). Decolonising online development studies? Emancipatory aspirations and critical reflections - a case study, Third World Quarterly, 38: 2

Stenbom, S., (2018). A systematic review of the Community of Inquiry survey. The Internet and Higher Education, 39, 22-32.

Swan, K., \& Shih, L. F. (2005). On the nature and development of social presence in online course discussions. Journal of Asynchronous Learning Networks, 9(3), 115-136.

Traphagan, T., Kucsera, J., \& Kishi, K. (2010). Impact of class lecture webcasting on attendance and learning. Educational Technology Research \& Development, 58(1), 1937.

Turpen, C., \& Finkelstein, N. D. (2010). The construction of different classroom norms during Peer Instruction: Students perceive differences. Physical Review Special Topics-Physics Education Research, 6(2), 20-23.

Vonderwell, S. and Zachariah, S., (2005). Factors that influence participation in online learning. Journal of Research on Technology in Education, 38(2), 213-230.

Wood, A. K., Galloway, R. K., Donnelly, R., \& Hardy, J. (2016). Characterizing interactive engagement activities in a flipped introductory physics class. Physical Review Physics Education Research, 12(1), 10-40.

Whatley, J., \& Ahmad, A. (2007). Using video to record summary lectures to aid students' revision. Interdisciplinary Journal of E-Learning and Learning Objects, 3, 185-196. 
Zhang, D., Zhou, L., Briggs, R. O., \& Nunamaker, J. F. (2006). Instructional video in elearning: Assessing the impact of interactive video on learning effectiveness.

Information \& Management, 43, 15-27. 